\title{
Amine and peptide hormone production by lung carcinoid: a clinicopathological and immunocytochemical study
}

\author{
FRED T BOSMAN, ${ }^{*}$ A BRUTEL DE LA RIVIERE, $\uparrow$ RWM GIARD, $\ddagger$ AAJ VERHOFSTAD,$\S$ \\ G CRAMER-KNIJNENBURG $\ddagger$ \\ From the *Department of Pathology, University of Limburg, the †Department of Cardiothoracic Surgery, \\ University of Leiden, the $¥$ Department of Pathology, University of Leiden, and the §Department of Anatomy \\ and Embryology, University of Nijmegen, The Netherlands
}

SUMMARY A consecutive series of 38 lung carcinoid tumours (36 surgical and two necropsy specimens) was studied. Histopathological features and amine and peptide hormone immunoreactivity were correlated with gross characteristics (size, location) and clinical data. Peripheral carcinoids were detected a decade later than central carcinoids and tended to be bigger. In general, the histological characteristics of peripheral and central carcinoids were similar; atypical features, however, were more common in peripheral carcinoids.

Most carcinoids contained many argyrophilic cells $(58 \%)$. Although argentaffinic cells were not found, serotonin immunoreactive cells were present in $32 \%$ of the tumours. Peptide hormone immunoreactivity (adrenocorticotrophic hormone (ACTH), calcitonin, somatostatin, gastrin) was rare. In one case massive ACTH production had caused clinically manifest Cushing's syndrome. In two other cases few ACTH immunoreactive cells were found and in one case calcitonın immunoreactive cells were present.

The relative rarity of hormone production in lung carcinoids and the predominantly benign course of the tumour preclude the use of peptide hormone production as a prognostic indicator.

Carcinoid tumours are relatively rare in the lung, comprising less than $1 \%$ of all pulmonary neoplasms. ${ }^{1}$ Most of these tumours arise in the main bronchi, but carcinoids may also occur in the periphery of the lung. Central (bronchial) carcinoids usually show architectural and cytonuclear features typical of these neoplasms. ${ }^{2}$ Peripheral carcinoids, however, regularly show more anaplastic features such as increased nuclear pleomorphism and hyperchromasia, increased mitotic activity, and architectural disorganisation. ${ }^{3}$ Furthermore, spindle cell variants occur more often. These atypical carcinoids have been reported to metastatise more frequently. ${ }^{45}$ Based on these findings atypical carcinoids have been tentatively designated as intermediate between typical carcinoids and the neuroendocrine type of small cell carcinoma. ${ }^{6-8}$

Although carcinoid tumours are regarded as neuroendocrine tumours, ${ }^{9}$ their association with clinically evident endocrine syndromes is relatively

Accepted for publication 25 April 1984 rare.$^{10}$ Carcinoid syndrome due to serotonin production in a bronchial carcinoid is extremely rare. Immunocytochemical evidence of peptide hormone production has been reported both with ${ }^{10}$ and without clinically evident endocrine syndromes. ${ }^{11-14}$ Systematic studies of production of amines and peptide hormones by bronchial carcinoids are relatively scarce. ${ }^{14}$ We have therefore investigated the occurrence of serotonin and a variety of neurohormonal peptides in a series of bronchial carcinoids using indirect immunoperoxidase and immunofluorescence techniques. The histochemical results were correlated with gross (location, size) and microscopic (architecture, cytonuclear features) characteristics. The results indicate that peptide hormone production is relatively uncommon, but serotonin production (without clinically evident carcinoid syndrome) occurs much more often.

\section{Material and methods}

From the files of the department of pathology 36 
specimens of carcinoid lung tumour obtained during surgery (Department of Thoracic Surgery, University Medical Centre, Leiden) and two specimens found incidentally at necropsy were collected (covering the period 1956 to 1981). All tissue specimens had been fixed in $4 \%$ formaldehyde (neutral and buffered after 1971) and embedded in paraffin. Of the available material (usually only one or two blocks were available) one representative block was selected for histochemical studies.

From each block serial $4 \mu \mathrm{m}$ sections were cut. Sections were stained for argentaffin cells according to Solcia et al ${ }^{15}$ and for argyrophil cells according to Grimelius. ${ }^{16}$ The presence of peptide hormone immunoreactivity was investigated by immunocytochemistry using an indirect peroxidase labelled antibody method. ${ }^{17}$ Rabbit antisera to adrenocorticotrophic hormone (ACTH), calcitonin, somatostatin, and gastrin were used. Specificity of these antisera was tested in a solid phase enzyme immunoassay, ${ }^{17}{ }^{18}$ and all antisera were found to be monospecific. Controls for the immunocytochemical staining included replacement of the primary antibody by non-immune rabbit serum or by immune serum preabsorbed with the appropriate peptide hormone. In these control sections staining was never seen.

Serotonin immunoreactivity was tested with indirect immunofluorescence. Specificity of the rabbit antiserotonin antibody and details of the immunostaining procedure and control procedures have all been described previously. ${ }^{19}$ The presence of immunoreactivity for any one of the above mentioned substances was correlated with size, location, and histological appearances. Histological evaluation was performed by two of us and included semiquantitative scoring for the presence of infiltrative growth, growth pattern (nodular, trabecular, acinar, or non-distinct), nuclear pleomorphism, and the occurrence of mitoses. In addition the presence of calcification or ossification, or both, and of amyloid was noted.

Statistical analysis of the data was performed using Wilcoxon's test or the $\chi^{2}$ test.

\section{Results}

Two centrally located bronchial carcinoids were incidental necropsy findings. In one of these patients the cause of death was not related to the carcinoid. The other patient presented with Cushing's syndrome and died of postoperative complications after trans-sphenoidal resection of a presumed ACTH producing pituitary adenoma. The Cushing's syndrome, however, appeared to be caused by ectopic production of ACTH by the bronchial carcinoid,
Table 1 Type of surgical resection

Enucleation

Segmentectomy

Lobectomy

Bilobectomy

Pneumectomy

Lobectomy with sleeve resection

Sleeve resection only

Table 2 Location, age and sex distribution, and size of surgically resected lung carcinoid tumours

\begin{tabular}{lll}
\hline & Peripheral & Central \\
\hline Total & 19 & 15 \\
Men & $10(53 \%)$ & $3(20 \%)^{*}$ \\
Women & $9(47 \%)$ & $12(80 \%)^{*}$ \\
Mean age (yr) (range) & $50 \cdot 1(20-75)$ & $41 \cdot 6(17-65) \dagger$ \\
Median age (yr) & 56 & 44 \\
Size (cm) & $1 \cdot 9(0 \cdot 3-4)$ & $1 \cdot 6(0 \cdot 7-25) \ddagger$ \\
\hline
\end{tabular}

${ }^{*}$ Difference not significant ( $\chi^{2}$ test).

$\dagger p=0 \cdot 05$ (Wilcoxon's test).

$\ddagger$ Range.

which, owing to its small size, had not been detected.

Pathological specimens were available from 38 patients: 23 women $(61 \%)$ and 15 men $(39 \%)$ with a mean age of 43 years (women 40 years, men 47 years). For 34 patients clinical data were available: $24(70 \%)$ presented with respiratory symptoms related to the tumour. Carcinoid syndrome had not occurred in any of the patients, although two patients had raised urinary concentrations of 5-hydroxyindoleacetic acid. In one patient a carotid artery chemodectoma had been resected previously.

Table 1 lists the surgical procedures used. Lobectomy was the most frequently chosen operative procedure ( $45 \%$ of patients). Clinical and macroscopical characteristics of the tumours are given in Table 2. Peripheral tumours were found slightly more often than central tumours $(19 v 15)$. Peripheral tumours occurred equally often in men and women $(10 v 9)$. Central tumours, however, were four times more common in women $(12 v 3)$. Peripheral tumours tended to be slightly bigger than central tumours $1.9 v 1.6 \mathrm{~cm}$; this difference, however, was not significant. Peripheral tumours occurred at later age than central tumours.

Microscopically, most tumours were fairly circumscript, and sometimes surrounded by a pseudocapsule. Invasion into surrounding structures was not found more often in peripheral tumours than in central tumours. Most carcinoid tumours showed a mixture of two or more of the characteristic growth patterns (nodular, trabecular, acinar, or nondistinct). Nuclear pleomorphism was usually slight; in six tumours, all peripheral, moderate nuclear pleomorphism was present. A noticeable increase in mitotic activity was found in only two tumours, both peripheral. Tumours composed predominantly of 
spindle cells were not encountered in this series. Calcification was found in five tumours, in four in combination with osseous metaplasia (Fig. 1). All but one of these tumours were peripheral. Amyloid was identified (congo red positive with green birefringence) in six tumours (three central, three peripheral).

In 28 cases sufficient material was available for additional histochemical and immunohistochemical staining; the findings are listed in Table 3. None of the tumours contained argentaffin positive cells. In most tumours (22) argyrophilic cells were found. Occasionally, most of the tumour cells were argyrophilic. More frequently, however, argyrophilia was only focal (Fig. 2), and in some tumours a few argyrophilic cells were found scattered between negative cells. Argyrophilic tumours tended to occur more often in central than in peripheral tumours $(p<0 \cdot 06)$. No correlation was found between growth pattern and argyrophilia. Scattered serotonin immunoreactive cells were found in 12 tumours (Fig. 3). Serotonin tended to
Table 3 Histochemical characteristics of 28 lung carcinoid tumours

\begin{tabular}{lrrrrrr}
\hline & \multicolumn{2}{c}{ Peripheral } & & \multicolumn{2}{c}{ Central } & Total \\
\cline { 2 - 3 } & \multicolumn{1}{c}{$n$} & $\%$ & & $n$ & $\%$ & \\
\hline Argentaffin +ve & 0 & & & 0 & & 0 \\
Argyrophil +ve & 10 & 67 & & 12 & 92 & $22^{*}$ \\
Serotonin +ve & 5 & 33 & & 7 & 54 & $12 \dagger$ \\
ACTH +ve & 2 & 13 & & 1 & 8 & 3 \\
Calcitonin +ve & 1 & 7 & & 0 & & 1 \\
Somatostatin +ve & 0 & & & 0 & & 0 \\
Gastrin +ve & 0 & & & 0 & & 0 \\
Total & 15 & & & 13 & & 28 \\
\hline
\end{tabular}

${ }^{*} \mathrm{p}=0.06\left(\chi^{2}\right.$ test $)$

+ Not significant $\left(x^{2}\right.$ test).

$+\mathrm{ve}=$ positive.

occur more often in central (54\%) than in peripheral $(33 \%)$ carcinoids, although this difference was not significant. No correlation was found between argyrophilia and serotonin immunoreactivity. Immunoreactive peptide hormones were rarely encountered: ACTH immunoreactivity occurred in two peripheral and one central carcinoids and cal-

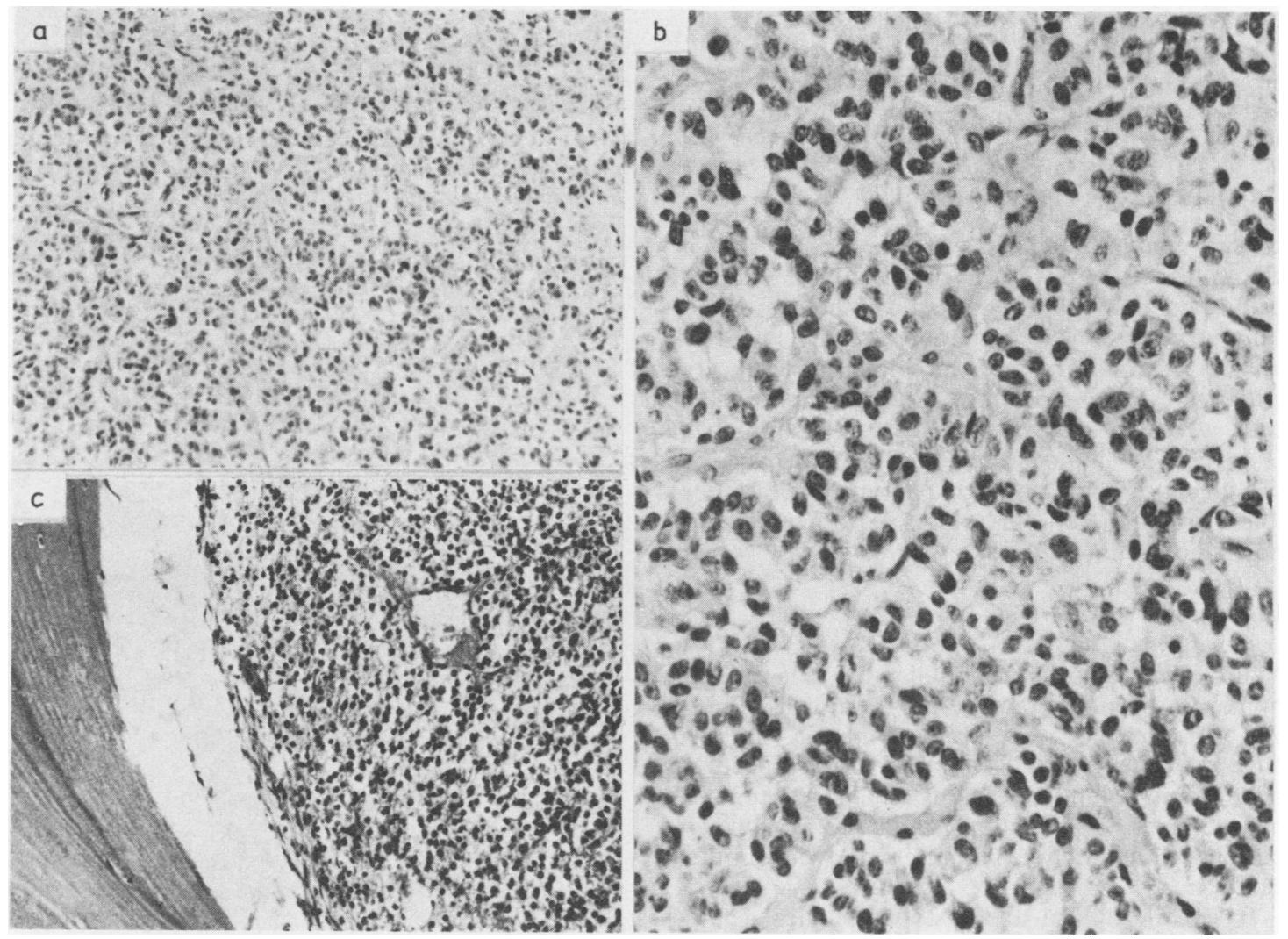

Fig. 1 Histological features of lung carcinoid tumours. (a) Nodular and trabecular growth pattern. Haematoxylin and eosin. Original magnification $\times 40$. (b) Same tumour, cytonuclear detail. Haematoxylin and eosin. Original magnification $\times 250$. (c) Focal osseous metaplasia. Haematoxylin and eosin. Original magnification $\times 40$. 


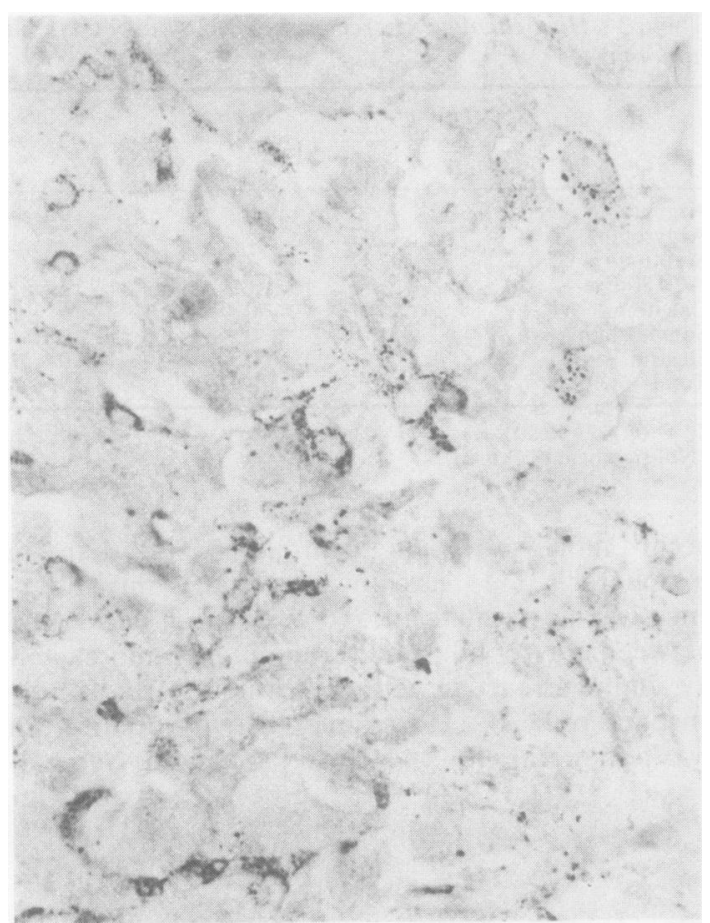

Fig. 2 Argyrophil positive cells in a lung carcinoid tumour. Note intercellular heterogeneity in silver reactivity. Grimelius. Original magnification $\times 400$.

citonin immunoreactivity in one peripheral carcinoid. In the ACTH producing carcinoid with clinically evident Cushing's syndrome the majority of tumour cells showed immunoreactivity (Fig. 4). In the other ACTH reactive carcinoid and in the calcitonin reactive carcinoid a few immunoreactive cells were scattered among negative tumour cells (Fig. 5). The limited number of peptide hormone producing tumours precluded an analysis of a possible correlation between growth pattern and peptide hormone production.

\section{Discussion}

Neuroendocrine cells are found in the mucosa of the human respiratory tract. ${ }^{2021}$ In these cells production of serotonin, calcitonin, bombesin, and leuenkephalin has been documented. ${ }^{21-25}$ It is generally believed that lung carcinoids, small cell tumours, neuroendocrine carcinomas, and presumably also peripheral pulmonary tumourlets derive from these cells. ${ }^{13}$

Based on clinical and histopathological characteristics some investigators ${ }^{626}$ have distinguished between typical carcinoids, which comprise the neoplasms with the morphological characteristics classically ascribed to carcinoids, and atypical carcinoids.

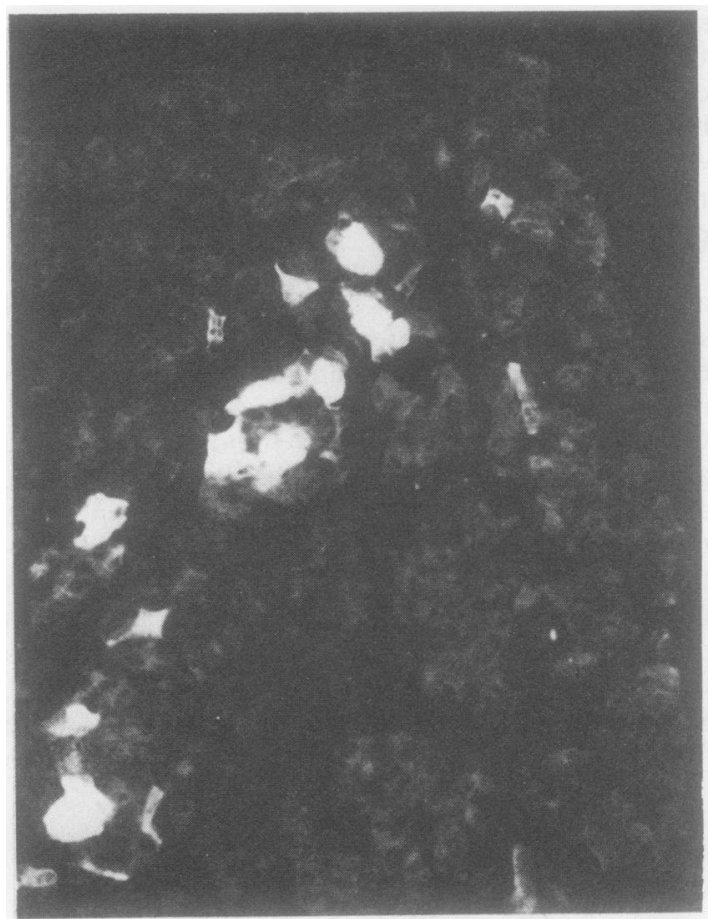

Fig. 3 Serotonin immunoreactivity in lung carcinoid. Only scattered cells are stained. Indirect immunofuorescence, antiserotonin. Original magnification $\times 250$.

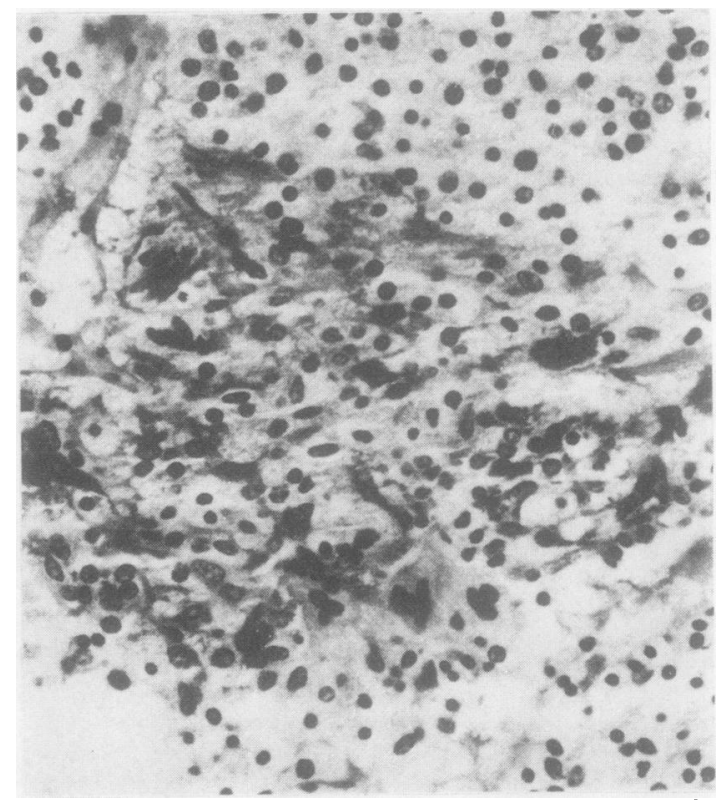

Fig. 4 ACTH immunoreactivity in a lung carcinoid with clinical evidence of Cushing's syndrome. Note the occurrence of a few intensely stained cells. Indirect immunoperoxidase staining, anti-ACTH. Original magnification $\times 250$. 


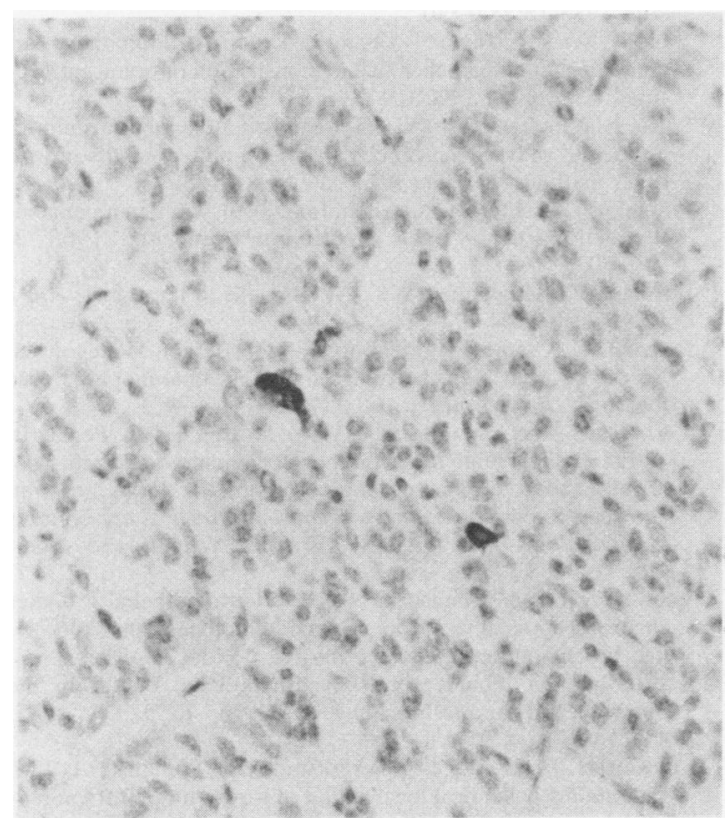

Fig. 5 Scattered calcitonin immunoreactivity in a lung carcinoid. Indirect immunoperoxidase, anticalcitonin. Original magnification $\times 250$.

In this latter category the neoplasms showed a predominantly solid (nodular or trabecular) growth pattern, foci of necrosis, markedly pleomorphic and hyperchromatic (occasionally spindle shaped) nuclei, and numerous mitoses. The prognosis of atypical carcinoids is significantly worse than that of typical carcinoids. ${ }^{6}$ Based on these findings it was proposed that atypical carcinoids might constitute a category of neoplasms intermediate between typical carcinoids and small cell carcinoma. ${ }^{620}$

Since atypical carcinoids appear to be located more often in the periphery of the lung, ${ }^{56}$ we paid special attention to possible differences between central and peripheral carcinoids in our series. We found a slight overall preponderance in women, which was caused solely by the fact that central carcinoids occurred four times more often in women compared with men. With regard to age distribution, peripheral carcinoids were detected about a decade later than central carcinoids (mean age 50.1 v 41.6 years). Central carcinoids, which often show polypoid endobronchial growth, may cause respiratory symptoms relatively early and therefore stand a better chance of early detection than peripheral carcinoids. The finding that central carcinoids tend to be smaller than peripheral carcinoids is in line with this assumption. Overall architectural and cytonu- clear features of peripheral and central carcinoids were remarkably similar, but we did find several differences. Firstly, atypical nuclear features occurred only in peripheral carcinoids (nuclear pleomorphism in six and increased mitotic activity in two of 19 tumours). Secondly, calcification occurred more often in peripheral than in central carcinoids and, finally, argyrophilia or serotonin immunoreactivity, or both, tended to occur more often in peripheral than in central carcinoids.

The studies of Ranchod and Levine ${ }^{5}$ on spindle cell carcinoids and of Mills $e^{2} a^{6}$ on atypical carcinoids suggest that a majority of peripheral pulmonary carcinoid tumours show these features. Our findings indicate that, although atypical features such as nuclear pleomorphism and increased mitotic activity do occur more frequently in peripheral than in central pulmonary carcinoids, the majority of peripheral carcinoid tumours seem to be morphologically indistinguishable from central carcinoid tumours. Whether or not the location of pulmonary carcinoids is relevant for prognosis remains uncertain and needs to be determined in a large series with long follow up.

In the present series serotonin immunoreactivity occurred relatively frequently, as was reported previously $^{14}$ despite the fact that none of the tumours contained argentaffin positive cells. Immunocytochemistry appears to be more sensitive for the detection of serotonin than argentaffin staining. ${ }^{27}$ The number of serotonin immunoreactive cells was usually rather low, which may explain why the carcinoid syndrome does not occur in pulmonary carcinoids. Peptide hormone immunoreactivity was rarely encountered, although testing for a wider range of neurohormonal peptides might have revealed more hormonally active tumours. Indeed, recent reports ${ }^{1314}$ indicate that neurohormonal peptides such as bombesin and pancreatic polypeptide may be detected more frequently. Our findings with regard to calcitonin immunoreactivity are in disagreement with those of Cooney et al, " who detected calcitonin (using our antibody) in six of 22 pulmonary carcinoids, four of which also showed foci of ossification. Since in the present study ossification did not occur together with calcitonin production we believe that a causal relation as postulated by Cooney et al" is unlikely. ACTH production, which may rarely cause Cushing's syndrome, ${ }^{10}$ appears to be equally rare in pulmonary carcinoids. The paucity of peptide hormone immunoreactivity in these neoplasms precludes conclusions regarding possible relations between hormonal activity and long term prognosis. Considering the predominantly benign course of these neoplasms, ${ }^{13}$ however, it is unlikely that neurohormonal production will appear to be an 
important prognostic factor.

In conclusion, we have shown that although peripheral and central pulmonary carcinoids are remarkably similar, atypical histological features tend to occur predominantly in peripheral tumours. Pulmonary carcinoids often produce serotonin, but peptide hormone immunoreactivity is relatively uncommon.

\section{References}

' Godwin RA. Carcinoid tumors. Cancer 1975;36:56-9.

${ }^{2}$ Jones RA, Dawson IMP. Morphology and staining patterns of endocrine cell tumours in the gut, pancreas and bronchus and their possible significance. Histopathology 1977; 1:137-50.

${ }^{3}$ Bonikos DS, Bensch KG, Janiplis RW. Peripheral pulmonary carcinoid tumors. Cancer 1976;37:1469-77.

${ }^{4}$ Churg A. Large spindle cell variant of peripheral bronchial carcinoid tumor. Arch Pathol Lab Med 1977;101:216-8.

${ }^{5}$ Ranchod M, Levine GD. Spindle cell carcinoid tumors of the lung. A clinicopathological study of 35 cases. Am J Surg Pathol 1980;4:315-31.

- Mills SE, Walker AN, Copper PH, Kron IL. Atypical carcinoid tumor of the lung. A clinicopathological study of 17 cases. Am J Surg Pathol 1982;6:643-54.

' Fisher ER, Palekar A, Paulson JD. Comparative histopathological, histochemical, electron microscopic and tissue culture studies of bronchial carcinoids and oat cell carcinomas of lung. J Clin Pathol 1978;69:165-72.

${ }^{8}$ McDowell EM, Barrett LA, Trump BF. Observations on small granule cells in adult human bronchial epithelium and in carcinoid and oat cell tumors. Lab Invest 1976;34:202-6.

${ }^{4}$ Corrin B. Lung endocrine tumours. Invest Cell Pathol 1980; 3:195-206.

${ }^{10}$ Cohen RB, Toll GD, Castleman B. Bronchial adenomas in Cushing's syndrome, their relation to thymomas and oat cell carcinomas associated with hyperadrenocorticison. Cancer 1960; 13:812-7.

" Cooney T, Sweeney EC, Luke D. Pulmonary tumours: a comparative regional study. J Clin Pathol 1979;32:1100-9.

12 Curz E, Chan W, Kay JM, Camberlain DW. Immunoperoxidase staining for serotonin, bombesin, calcitonin and leuenkephalin in pulmonary tumorlets, bronchial carcinoids and oat cell carcinomas. Lab Invest 1982;46:16A.

${ }^{13}$ Gould VE, Linnoila RI, Memoli V, Warren WH. Neuroendocrine cells and neuroendocrine neoplasms of the lung. Pathol
Ann 1983; 18:287-330.

14 Yang K, Wick T, Taylor I, Cheng L, Lewin KJ. Pulmonary carcinoid. Immunohistochemical demonstration of brain-gut peptides. Cancer 1983;52:819-23.

is Solcia E, Capella C, Vassallo G. Lead hematoxylin as a stain for endocrine cells. Significance of staining and comparison with other methods. Histochemie 1969;20:116-26.

${ }^{16}$ Grimelius L. A silver nitrate stain for $\alpha_{2}$-cells in human pancreatic islets. Acta Societatis Medicorum Upsalienses 1968;73: 243-70.

17 Bosman FT, Louwerens JWK. APUD cells in teratomas. Am J Pathol 1981;104:174-80.

${ }^{18}$ Bosman F.T, Cramer-Knijnenburg G, Van Bergen-Henegouw J. Efficiency and sensitivity of indirect immunoperoxidase methods. Histochemistry 1983;77:185-94.

19 Verhofstad AAJ, Steinbusch HWM, Joosten HWJ, Penke B, Varga J, Goldstein M. Immunocytochemical localization of noradrenaline, adrenaline and serotonin. In: Polak JM, van Noorden S, eds. Immunocytochemistry: Practical applications in pathology and biology. Bristol: Wright and Sons, 1983:143-68.

${ }^{20}$ Lauwerijns JM, Peuskens JC. Neuroepithelial bodies (neuroreceptor of secretory organs) in human infant bronchial and bronchiolar epithelium. Anat Rec 1972;172:471-82.

${ }^{21}$ Lauwerijns JM, Goddeerin P. Neuroepithelial bodies in the human child and adult lung. Am Rev Resp Dis 1975; 111:469-76.

${ }^{22}$ Lauwerijns JM, De Bock V, Verhofstad AAJ, Steinbusch HWM. Immunohistochemical localization of serotonin in intrapulmonary neuroepithelial bodies. Cell Tissue Res 1982;226:215-23.

${ }^{23}$ Becker KL, Monaghan KG, Silva O. Immunocytochemical localization of calcitonin in Kulchitsky cells of the lung. Arch Pathol Lab Med 1980;104: 196-8.

${ }^{24}$ Cutz E, Chan W, Track VS. Bombesin, calcitonin and leuencephalin immunoreactivity in the human lung. Experienta 1981;37:765-7.

${ }^{25}$ Wharton J, Polak JM, Bloom SR. Bombesin-like immunoreactivity in the lung. Nature 1978;273:769-70.

${ }^{26}$ Antigoni MG, Woolner LB, Beratz RE. Atypical carcinoid tumors of the lung. J Thorac Cardiovasc Surg 1972;64:41321.

${ }^{27}$ Cuello AC, Wells C, Chaplin AJ, Milstein C. Serotonin immunoreactivity in carcinoid tumours demonstrated by a monoclonal antibody. Lancet 1982;i:771-3.

Requests for reprints to: Dr FT Bosman, Department of Pathology, Biomedical Center, University of Limburg, PO Box 616, 6200 MD Maastricht, The Netherlands. 